$\mathbb{B}_{\text {Dissei }} \mathfrak{A}$

ISSN: 1983 2435

\title{
Estratégias de relativização em cartas oficiais norte-rio-grandenses dos séculos XVIII e XIX
}

\author{
Relativization Strategies in Official Letters from Rio Grande do \\ Norte in the 18th and 19th centuries
}

\author{
Aline Priscilla de Albuquerque Braga* \\ alinepalbuquerquebraga@gmail.com \\ Universidade Federal do Rio Grande do Norte \\ Edvaldo Balduino Bispo ${ }^{* *}$ \\ edbbispo@gmail.com \\ Universidade Federal do Rio Grande do Norte
}

RESUMO: Neste artigo, investigamos a frequência de uso das orações relativas do Português Brasileiro (PB) em perspectiva histórica, com vistas a identificar possíveis motivações funcionais subjacentes à recorrência de cada uma delas (padrão, cortadora e copiadora). Os dados foram extraídos das amostras de 86 cartas oficiais, provenientes da plataforma de corpora do projeto Para a História do Português Brasileiro (PHPB), que circularam no estado do Rio Grande do Norte entre os séculos XVIII e XIX. Corroborando os pressupostos teóricos funcionalistas de que as formas linguísticas são motivadas por elementos de ordem sociointeracional e cognitiva, constatamos que o predomínio de orações relativas canônicas, no corpus selecionado, justifica-se, entre outras razões, pelas características do gênero carta oficial, ao passo que à recorrência a relativas do tipo não padrão subjazem fatores como princípio da economia de esforço e expressividade retórica.

PALAVRAS-CHAVE: Estratégias de relativização. Linguística Funcional Centrada no Uso. Diacronia.

ABSTRACT: In this paper, we investigate the frequency of the use of relative clauses in Brazilian Portuguese (BP) from a historical perspective. We aim to identify possible functional motivations underlying the instances of each strategy (standard, copiadora and cortadora). The data are samples of 86 official letters from the corpora Para a História do Português Brasileiro (PHPB) project, and they were written in the 18th and 19th centuries in the state of Rio Grande do Norte, Brazil. Corroborating the theoretical assumptions of Linguística Funcional Centrada no Uso according to which linguistic forms are motivated by communicative and cognitive aspects, we attested that the predominance of standard relative clauses in the selected corpus is due, among other things, to the characteristics of the genre official letters. We also

\footnotetext{
* Mestranda do Programa de Pós-graduação em Estudos da Linguagem da Universidade Federal do Rio Grande do Norte; Bolsista do CNPq

"* Doutor em Estudos da Linguagem e Professor do Departamento de Letras e do Programa de Pósgraduação em Estudos da Linguagem, Universidade Federal do Rio Grande do Norte
} 
$\mathbb{B}_{\text {dissei }} \mathcal{A}$

ISSN: 1983 2435

attested that underlying the use of non-standard relative clauses is the principle of economy of effort and rhetoric expressiveness.

KEYWORDS: Relativization Strategies. Linguística Funcional Centrada no Uso. Diachrony.

\section{Considerações Iniciais}

Estudos tipológicos, a exemplo de Greenberg (1966), Keenan e Comrie (1977) e Croft (1990), demonstram a existência de propriedades comuns à maioria das línguas estudadas, os chamados universais linguísticos. Um desses fenômenos, altamente produtivo nas mais variadas línguas, é a oração relativa, a qual codifica a necessidade de delimitar, especificar ou comentar o conteúdo de um elemento nominal (BISPO, 2009, p. 53).

De acordo com a abordagem descritiva proposta por Perini (1998), a sentença relativa (tradicionalmente designada de "oração adjetiva") constitui-se como um elemento subordinado ao núcleo de um sintagma nominal ao qual serve de modificador. Como características desse tipo de construção, Perini (1998, p.152) aponta:

(a) a presença de um pronome relativo, precedido às vezes de uma preposição; (b) a presença de uma estrutura oracional aparentemente incompleta, logo após o relativo; e (c) a articulação de um elemento nominal (parte de um $S N$ ) + o pronome relativo + a estrutura oracional mencionada, formando uma sequência que é um SN. (PERINI, 1998, p. 152, grifos do autor).

Vejamos, como ilustrações de sentenças relativas, as cláusulas destacadas em (1) e em (2).

(1) "Abri a porta do carro em que me encontrava e me puz à caminhar até o carro dele, só não podia imaginar que ao chegar até o carro dele iria encontrar minha irmã ao lado dele agora imagine só a situação como não ficou" (Corpus D\&G Rio de Janeiro, língua escrita $)^{1}$

\footnotetext{
1 As ocorrências extraídas do D\&G Rio de Janeiro aparecem com indicação distinta daquelas oriundas do $D \& G$ Natal, pois o corpus carioca não foi publicado.
} 
(2) "Acontece que a família que o Malarzarte acompanhava ficou hospedada no mais luxuoso hotel da cidade e este teve a honra de, pela primeira vez na sua vida, pisar num ambiente tão requintado". (Corpus D\&G Natal, língua escrita, 1998, p. 166)

Em ambos os casos, as orações destacadas estão aparentemente incompletas (em (1), há a ausência do complemento circunstancial e, em (2), do objeto direto, elementos solicitados pelos verbos das orações em destaque) e aparecem introduzidas pelo pronome que. Esse relativo retoma os sintagmas nominais carro, em (1), e família, em (2) e exerce, na oração relativa, as funções sintáticas que nelas faltam. Na cláusula assinalada em (1), a presença da preposição em antes do pronome deve-se à natureza da função sintática por ele desempenhada, no caso, adjunto adverbial de lugar; em (2), de modo diferente, o relativo atua como objeto direto de acompanhar, não sendo, portanto, precedido de preposição obrigatória.

O tratamento que a gramática tradicional confere às orações relativas deixa de considerar que, no uso real da língua, nem sempre os falantes restringem suas escolhas à modalidade padrão, quando lançam mão desse tipo de estrutura. $\mathrm{Na}$ comunicação cotidiana, prevalece o uso pouco monitorado da língua e, por isso, é comum que haja a recorrência a sentenças relativas cortadoras e copiadoras. $O$ emprego de uma estratégia não canônica em vez de uma canônica correspondente está relacionado, conforme discutimos neste artigo, a fatores de natureza diversa: cognitiva, discursiva e pragmática. As amostras (3), e (4) trazem ocorrências de relativas não canônicas, cortadora e copiadora, respectivamente.

(3) "... e em frente a beliche têm uma pequena estante que colocamos muitas revistas e nossos instrumentos de músicas e na parede do lado da beliche possui vários quadros que costumo criar no computador. (Corpus D\&G Rio de Janeiro, língua escrita)

(4) “... aí tinha uma... uma vidente... uma espírita... que ela... enrolava o povo sabe? aí... tem uma parte que ela tá... falando assim... tá com os clientes... né?" (Corpus D\&G Natal, língua falada, 1998, p. 237)

$\mathrm{Na}$ oração destacada em (3), a preposição regida por colocar (em), que, conforme prevê a tradição normativa, deveria preceder o pronome relativo, foi suprimida, "cortada", daí a denominação dessa oração como cortadora. Já em (4), a 
oração relativa marcada é copiadora, pois, em sua estrutura, o antecedente do relativo que (uma espírita) é retomado (copiado) pelo pronome correferente ela.

Embora as estratégias de relativização não canônicas já tenham sido objeto de estudo de alguns pesquisadores, como Mollica (1977), Tarallo (1983), Correa (1998), Burgos (2003), Varejão (2006) e Bispo (2009), a maioria das pesquisas realizadas trata a questão sob um viés variacionista, sendo apenas os estudos desenvolvidos por Bispo $(2003,2007,2009,2014)$ de base funcionalista. Há também uma carência de pesquisas diacrônicas acerca desse tema; com exceção dos trabalhos realizados por Tarallo (1983) e Bispo (2014), os outros estudos conhecidos, até então, possuem orientação sincrônica.

Neste artigo, em particular, discutimos a frequência de uso dos mecanismos de relativização, canônicos ou não, do português escrito no estado do Rio Grande do Norte, em perspectiva histórica. Em linhas gerais, objetivamos investigar o uso das estratégias de relativização em cartas oficiais norte-rio-grandenses escritas durante os séculos XVIII e XIX, correlacionando-o a motivações interacionais e cognitivas implicadas. De modo específico, pretendemos: i) verificar a frequência de uso de cada uma das estratégias de relativização nas sincronias consideradas; ii) e distintas; ii) identificar e analisar motivações de natureza comunicativa e cognitiva envolvidas no uso dessas estratégias.

Quanto à fundamentação teórica, adotamos os pressupostos da Linguística Funcional Centrada no Uso (doravante, LFCU), abordagem que congrega contribuições da Linguística Funcional de vertente norte-americana, da Linguística Cognitiva e da Psicolinguística. O material analisado compõe o corpus mínimo do projeto Para a História do Português Brasileiro (PHPB), sendo selecionadas 86 cartas oficiais manuscritas nos séculos XVIII e XIX, referentes ao estado do Rio Grande do Norte.

\section{Pressupostos teóricos}

Conforme mencionado, nossa investigação sustenta-se teoricamente na LFCU $^{2}$. Essa abordagem resulta da união dos estudos em Linguística Funcional,

${ }^{2}$ Denominação cunhada pelo Grupo de Pesquisa Discurso \& Gramática (D\&G) a partir do termo Linguística Centrada no Uso proposto por Martelotta (2011) como correspondente a Usage-Based 
inspirados em autores como Givón (1979, 1995, 2001), Hopper (1987), Bybee (2010), Traugott (2004), entre outros, de pesquisas realizadas por representantes da Linguística Cognitiva, como Langacker (1987) e Lakoff e Johnson (2002), além de contribuições de psicolinguistas, a exemplo de Taylor (1995) e Tomasello (1998).

Ampliando os limites das abordagens que elegem como foco de análise apenas os aspectos formais das línguas, como o Estruturalismo e o Gerativismo, a LFCU reconhece que elementos cognitivos, semânticos, pragmáticos e discursivos exercem influência sobre a configuração dos padrões gramaticais. Por conseguinte, o interesse de investigação das pesquisas fundamentadas nessa vertente teórica ultrapassa os limites da estrutura gramatical, buscando nos aspectos ligados ao processamento linguístico e, sobretudo, à experiência humana no contexto de suas atividades sociointeracionais e culturais a motivação para a organização da gramática e a codificação linguística (FURTADO DA CUNHA; BISPO; SILVA, 2013).

Assumimos, portanto, o postulado de que a estrutura linguística emerge do uso (BYBEE, 2010). Nesse sentido, a configuração exibida pelas formas linguísticas é motivada pela função comunicativa que elas desempenham na interação discursiva.

Ainda de acordo com a perspectiva teórica norteadora deste trabalho, a língua é compreendida como uma estrutura maleável, sujeita às pressões de uso e constituída de um código parcialmente arbitrário. Assim, entendemos a gramática como um produto inacabado, um sistema adaptativo e emergente em contínuo processo de variação e mudança, de modo a atender a necessidades cognitivas e/ou interacionais de seus usuários. O seu estudo, portanto, deve ser realizado em simbiose com o discurso, uma vez que ambos interagem e se influenciam mutuamente (FURTADO DA CUNHA; BISPO; SILVA, 2013).

Dentre os princípios e categorias analíticas da LFCU, faremos uso dos princípios de iconicidade e de marcação. O princípio de iconicidade, conforme referido por Givón (1984), diz respeito à correlação natural entre as estruturas morfossintáticas de uma língua (forma) e as funções semânticas e pragmáticas a que correspondem (conteúdo). Nos moldes givonianos, a iconicidade constitui-se por três subprincípios: i) quantidade, segundo o qual quanto maior a quantidade de 
informação, maior a quantidade de forma linguística para codificá-la; assim, a complexidade da expressão reflete de algum modo, a complexidade do pensamento: aquilo que é mais simples e previsível, do ponto de vista conceitual, manifesta-se por meio de estruturas menos complexas); ii) integração ou proximidade, o qual estabelece que os conteúdos que estão mais próximos mentalmente também estão mais próximos no nível da codificação; e iii) ordenação linear, o qual prevê que a ordenação das orações no discurso tende a refletir a importância que elas têm e/ou a sequência temporal em que os eventos por elas codificados foram percebidos.

Esse princípio atua, portanto, motivado por questões de clareza e transparência, de modo a reduzir a opacidade entre a forma linguística e seu correlato semântico e/ou pragmático.

Em direção oposta ao princípio de iconicidade, atua a lei de menor esforço. Proposto por Zipf (1935, p. 29, apud HAIMAN, 1985, p. 167), esse princípio indica que há uma relação entre a frequência de uso e a extensão da estrutura linguística, sendo "a alta frequência a causa de pequeno tamanho". Em relação a nosso objeto de investigação, consideramos que a recorrência às estratégias de relativização pode relacionar-se a pressões competidoras: ora concorre para maior clareza, expressividade, ora atende a necessidades de praticidade e economia.

O princípio de marcação, por sua vez, relaciona-se "à presença vs ausência de uma propriedade nos membros de um par contrastante de categorias linguísticas" (FURTADO DA CUNHA, 2001, p. 60). São três os critérios básicos defendidos por Givón (1990), para distinguir uma categoria marcada de uma não marcada, a saber: (i) complexidade estrutural: a estrutura marcada tende a ser mais complexa - ou maior - que a não marcada correspondente; (ii) complexidade cognitiva: a estrutura marcada normalmente é mais complexa cognitivamente (em termos de atenção, esforço mental ou duração de processamento) que a correspondente não marcada; e (iii) distribuição de frequência: a categoria marcada tende a ser menos frequente, portanto mais saliente cognitivamente, que a não marcada.

Outro princípio, caro a esta análise, é o da marcação expressiva, proposto por Dubois e Votre (1994). Consoante essa proposição, há um equilíbrio entre o esforço de codificação que certas estruturas linguísticas provocam e a expressividade/ eficácia que se obtém a partir de seu uso. De acordo com os autores, em contraponto ao que enuncia o princípio da marcação, um procedimento discursivo 
marcado expressivamente pode: a) ser menos elaborado e menos longo; b) ser mais frequente; e c) reduzir ou anular o esforço de codificação.

Por fim, consideramos ainda, para esta investigação, a interface Funcionalismo/Linguística Textual na medida em que reconhecemos a seleção dos recursos linguísticos passível de ser influenciada pelas características composicionais do gênero e das sequências textuais em que ocorrem. Tais características envolvem, dentre outros fatores, diferentes graus de formalidade, decorrentes da distância social entre os interlocutores, das intenções comunicativas múltiplas e das práticas sociais diversas.

\section{Questões metodológicas}

Consoante os pressupostos teórico-metodológicos da LFCU, nos quais este trabalho está circunscrito, "aferir a frequência de ocorrência de um dado fenômeno linguístico é importante, já que assinala aquilo que o consagra como estratégia de comunicação em um determinado contexto" (FURTADO DA CUNHA; BISPO; SILVA, 2013, p. 21). Além disso, os pesquisadores orientados por essa corrente teórica buscam verificar de que maneira fatores de natureza diversa (cognitivos, semânticos e discursivo-pragmáticos) aumentam ou inibem a manifestação do fenômeno investigado em diferentes contextos comunicacionais.

Desse modo, do ponto de vista metodológico, esta pesquisa apresenta um caráter tanto quantitativo/descritivo como qualitativo/explicativo. Assim, buscamos não só mensurar e caracterizar as ocorrências de orações relativas encontradas no corpus, mas também esclarecer as possíveis motivações interacionais, cognitivas e pragmáticas implicadas no uso das estratégias de relativização, sobretudo das não canônicas.

O corpus utilizado para esta análise é composto por 86 cartas oficiais norterio-grandenses escritas nos séculos XVIII e XIX. Caracterizadas pelo registro formal de linguagem, as cartas analisadas foram extraídas da plataforma de corpora pertencente ao projeto Para a História do Português Brasileiro (PHPB) ${ }^{3}$.

De modo comparativo, observamos os percentuais das ocorrências de orações relativas na primeira e segunda metades de cada século, considerando três

${ }^{3}$ Cf. https://sites.google.com/site/corporaphpb/. 
fatores: o tipo de relativa (canônica, cortadora ou copiadora), o pronome relativo utilizado para subordiná-la à oração principal e a função sintática que o pronome exerce no interior da oração relativa. Por fim, realizamos a análise das ocorrências, discutindo motivações comunicativas e cognitivas implicadas no uso de cada uma das estratégias de relativização.

\section{Análise dos dados}

Nesta seção, expomos os resultados decorrentes do levantamento quantitativo e fazemos a discussão desses dados à luz dos princípios de iconicidade, marcação e expressividade, e em termos de motivações para o uso das estratégias de relativização. Na organização dos dados, conforme explicitado na seção anterior, consideramos o tipo de estratégia utilizada, ambiente sintático em que ocorreu a relativa (preposicionado ou não preposicionado) e a sincronia a que correspondem (séculos XIX e XX, primeira e segunda metades). Os resultados são os que apresentamos na Tabela 1.

Tabela 1: Ocorrências das relativas em cartas oficiais norte-rio-grandenses por sincronia - séculos XVIII e XIX.

\begin{tabular}{|c|c|c|c|c|c|c|c|c|c|}
\hline \multirow[t]{2}{*}{ Ambiente } & \multirow[t]{2}{*}{ Estratégia } & \multicolumn{2}{|c|}{$1701-1750$} & \multicolumn{2}{|c|}{$1751-1800$} & \multicolumn{2}{|c|}{$1801-1850$} & \multicolumn{2}{|c|}{$1851-1900$} \\
\hline & & $N$ & $\%$ & $\mathrm{~N}$ & $\%$ & $\mathrm{~N}$ & $\%$ & $\mathrm{~N}$ & $\%$ \\
\hline \multirow[t]{2}{*}{ Não prep. } & Canônica & 92 & $\overline{73,6}$ & $\overline{70}$ & 78,7 & 47 & 64,4 & 43 & 70,5 \\
\hline & Copiadora & - & & 1 & 1,1 & - & & - & \\
\hline \multirow[t]{3}{*}{ Prep. } & $\mathrm{RPP}^{4}$ & 25 & $\overline{20,0}$ & $\overline{14}$ & 15,7 & 23 & 31,5 & 15 & $\overline{24,6}$ \\
\hline & Cortadora & 8 & 6,4 & 3 & 3,4 & 3 & 4,1 & 3 & 4,9 \\
\hline & Copiadora & - & & 1 & 1,1 & - & & - & \\
\hline Total & & 125 & 100 & 89 & 100 & 73 & 100 & 61 & 100 \\
\hline
\end{tabular}

Foram identificadas 348 orações relativas no corpus, das quais $253(72,7 \%)$ com o pronome relativo em funções não preposicionadas - sujeito e objeto direto - e

\footnotetext{
${ }^{4}$ Relativa Preposicionada Padrão
} 
$95(27,3 \%)$ em funções preposicionadas. Quanto ao tipo de estratégia, a relativa canônica foi quase categórica nesses casos (252, ou seja, 99,6\%).

Conforme a hierarquia de acessibilidade proposta por Kennan e Comrie (1977), as funções sintáticas, em termos cognitivos, exibem a seguinte escala de complexidade (da menor para a maior): sujeito > objeto direto > objeto indireto > oblíquo > genitivo > comparativo. Assim, o elevado índice da estratégia canônica em nossos dados deve-se, entre outros fatores, à predominância do relativo nas funções de sujeito e objeto direto, os papéis sintáticos cognitivamente mais acessíveis aos falantes, segundo proposição desses autores. É preciso considerar que a relativa cortadora, por exemplo, só ocorre quando a função relativizada é preposicionada.

Nessa última situação, aliás, também atestamos a predominância da relativa preposicionada padrão, RPP, com 77 ocorrências (81\% do total), seguida pela cortadora, com 17 dados (18\%) e pela copiadora, com uma ocorrência (1\%).

A maior recorrência à RPP com o relativo em função preposicionada provavelmente se deve ao emprego da modalidade escrita, que implica uso mais monitorado da língua. Além disso, as cartas oficiais que compõem o corpus analisado possuem temática política, envolvem a defesa de um posicionamento e são destinadas à esfera pública. Assim, o emprego de estruturas mais formais, como é o caso da RPP, contribui para que o texto pareça, ao julgamento do leitor, dotado de maior credibilidade.

Acompanhando estudos anteriores, como os de Bispo (2007, 2009), observamos que a recorrência à cortadora em vez de sua correlata padrão também está relacionada à lei de menor esforço. Consideremos, para fins de comparação, a ocorrência em (5) e sua correlata padrão em (5a):

(5) A grandioza esmola que deV.Ex.a Recebi naproteçaõdefelixexito do emprego em que me axo de capitam mor do Rio Grande do Norte, é a que me alenta e emcaminha abuscar segunda vesospes deV.Ex.a e humilde mente rogarlhe maqueira continuar, am parandomenapertençaõ que aspiro de hir daqui p.aosiara grande ououtra qual quer parte queV. Magestade Fidelíssima pelasua real grandesa for servido mandarme (Carta Oficial - Rio Grande do Norte, $1^{\text {a }}$ metade do século XIX)

(5a) ... e emcaminha abuscar segunda vesospes deV.Ex.a e humilde mente rogarlhe maqueira continuar, am parandomenapertençaõ a que aspiro de hir daqui p.aosiara... 
A oração destacada em (5a) é mais complexa estruturalmente que a relativa em (5), dada a presença da preposição a. Cognitivamente, a relativa em (5a) também parece implicar maior complexidade de elaboração em relação à (5), dado que implica a seleção do verbo a ser utilizado (aspirar, no caso), o conhecimento de sua regência e a escolha da preposição a ser empregada antes do relativo. Da parte do leitor, também parece ser mais custoso processar a RPP de (5a) devido à recuperação/ identificação da relação entre o verbo e o pronome relativo, além do comportamento anafórico deste. Essa maior complexidade implicada na RPP, em termos estruturais e cognitivos, acaba por favorecer o uso da estratégia cortadora.

Levando em consideração o princípio da iconicidade, a ordem OSV das orações relativas de complemento contraria o subprincípio da integração, pois nelas há distanciamento entre o verbo e seu complemento, ou seja, conceitos mais integrados no plano cognitivo não se apresentam com maior grau de ligação morfossintática. A anteposição do complemento em relação ao verbo resulta em maior opacidade na relação entre esses elementos, e isso contribui para que a preposição não seja usada antes do pronome relativo.

Com relação às copiadoras encontradas no corpus, elas representam um percentual mínimo, com apenas dois casos, e também podem ser explicadas à luz dos princípios de marcação e de iconicidade. Vejamos a ocorrência em (6).

(6) Illmo ExmoSenhor Martinho de Mello e Castro II No dia 19de fevereiro deste presente anno to $=\mid$ mei posse desta capitania do Rio grande do Norte, da qual VEx.a mefes ahonra | ẽmcarregar o governo dela, achando esta piquena cidade esuas vezinhanças no $=\mid$ deploravel estado demayor compaichaõ com huma epidemia debexigas (Carta Oficial - Rio Grande do Norte, $2^{\circ}$ metade do século XVIII)

Observemos que, do ponto de vista estrutural, a copiadora implica uma maior complexidade tanto em relação à cortadora quanto à RPP correspondentes, por envolver a presença de um elemento cópia (ela, no caso em (6)). Entretanto, essa maior extensão na estrutura não significa que ela seja mais complexa cognitivamente. Isso porque esse tipo de oração possivelmente demanda menor esforço cognitivo, principalmente em seu processamento, pois o uso da cópia deixa 
mais transparente a relação, no caso de (6), entre nome (governo) e adjunto adnominal (dela).

A opção pelo uso de uma relativa copiadora, no caso de (6), contribui inclusive para a proximidade entre nome e adjunto (de posse). Parece atuar aqui o princípio de iconicidade, no que diz respeito ao subprincípio da integração, visto que os elementos mais próximos cognitivamente encontram-se também mais próximos estruturalmente.

Considerando o princípio da expressividade retórica ou da marcação expressiva, podemos dizer que há uma compensação entre o esforço para a produção de uma estrutura mais extensa e o efeito expressivo que com ela se obtém. A reiteração do antecedente do relativo facilita o processamento pelo interlocutor além de promover uma maior clareza, expressividade em termos comunicativos.

Conforme já demonstrado por outros estudos sobre estratégias de relativização, como Bispo (2003, 2007, 2009), reafirmamos a baixa ocorrência da copiadora no corpus utilizado pelo fato de ela ser, dentre as estratégias não canônicas, a mais estigmatizada, sobretudo quando se trata de dados linguísticos registrados na modalidade escrita e em um gênero textual marcado pela formalidade, como é o caso da carta oficial.

\section{Considerações finais}

Utilizando a perspectiva teórico-metodológica da LFCU, constatamos que o uso das estratégias de relativização em cartas oficiais norte-rio-grandenses, escritas nos séculos XVIII e XIX, é motivado por fatores de natureza cognitiva e interacional.

A predominância das estratégias padrão ocorre devido à distância social dos interlocutores, ao registro de linguagem que os textos deste corpus apresentam e à formalidade característica do gênero carta oficial. As estratégias não canônicas, embora em menor número, não são usos recentes no $\mathrm{PB}$, nem ocorrem de maneira aleatória, tampouco constituem meros "erros" ou "desvios à norma", como, comumente, alguns manuais de ensino apontam.

Com base na análise dos dados, a recorrência às estratégias de relativização não canônicas obedece a pressões competidoras: ora concorre para maior clareza e 
expressividade, no caso das copiadoras, ora atende a necessidades de praticidade e economia, no caso das cortadoras. Desse modo, é imperativo admitir a língua como um objeto dinâmico, cuja estrutura é moldada por elementos relativos ao domínio do discurso, da pragmática e da cognição.

As discussões empreendidas neste artigo contribuem, portanto, para uma melhor compreensão sobre o uso das orações relativas, sejam elas canônicas ou não, em produções escritas reais. Considerados os resultados, é possível compreender os pressupostos funcionalistas como facilitadores para o entendimento de como os usuários de uma língua codificam e organizam estruturalmente os enunciados durante um ato comunicativo.

Contudo, reconhecemos que ainda há muitos aspectos que precisam ser mais bem explorados acerca do uso de sentenças relativas, no âmbito funcional e em perspectiva diacrônica. Embora este estudo traga contribuições para as pesquisas linguísticas em textos norte-rio-grandenses, há necessidade de incluir outros gêneros textuais no corpus selecionado e analisar amostras escritas em outros séculos, para obter resultados mais completos acerca da correlação forma/função das sentenças relativas canônicas e não canônicas em situações reais de uso da língua.

\section{Referências}

BISPO, E. B. Relativa copiadora: uso, regularização e ensino. Dissertação (Mestrado em Estudos da Linguagem), Natal: Universidade Federal do Rio Grande do Norte, 2003.

- Oração adjetiva cortadora: análise de ocorrências e implicações para o $\overline{\text { ensino }}$ de português. Linguagem \& Ensino, v. 10, n. 1, p. 163-186, 2007.

. Estratégias de relativização no português brasileiro e implicações para o ensino: o caso das cortadoras. Tese (Doutorado em Estudos da Linguagem), Natal: Universidade Federal do Rio Grande do Norte, 2009.

. Orações relativas em perspectiva histórica: interface uso e cognição. Veredas, v. 18, n.1, p. 222-235, 2014.

BURGOS, L. E. S. de. Estratégias de uso das relativas em uma comunidade de fala afro-brasileira. Dissertação (Mestrado em Letras e Linguística), Salvador: Universidade Federal da Bahia, 2003.

BYBEE, J. Language, usage and cognition. Cambridge: CUP, 2010 
CORREA, V. R. Oração relativa: o que se fala e o que se aprende no português do Brasil. Tese (Doutorado em Linguística), Campinas: Universidade Estadual de Campinas, 1998.

CROFT, W. Typology and universals. Cambridge: Cambridge University Press, 1990.

DUBOIS, S.; VOTRE, S. Análise modular e princípios subjacentes do funcionalismo lingüístico: à procura da essência da linguagem. Rio de Janeiro: UFRJ, impresso, 1994.

FURTADO DA CUNHA, M. A. (Org.). Corpus Discurso e Gramática - a língua falada e escrita na cidade do Natal. Natal: EDUFRN, 1998.

Análise funcionalista de procedimentos discursivos. In: PASSEGGI, L.; OLIVEIRA, M. do S. (Orgs.) Lingüística e educação: gramática, discurso e ensino. São Paulo: Terceira Margem, 2001, p. 55-76.

;; BISPO, E. B.; SILVA, J. R. Linguística Funcional Centrada no Uso: conceitos básicos e categorias analíticas. In: CEZARIO, M. M.; FURTADO DA CUNHA, M. A. (Orgs.). Linguística centrada no uso: uma homenagem a Mário Martelotta. Rio de Janeiro/ Cataguases-MG: FAPERJ/Mauad, 2013, p. 13-39.

GIVÓN, T. On understanding grammar. New York: Academic Press, 1979.

Syntax: a functional-typological introduction. v. I, Amsterdam: John Benjamins, 1984.

Benjamins, 1990.

Syntax: a functional-typological introduction. v. II, Amsterdam: John Functionalism and grammar. Amsterdan: John Benjamins, 1995.

Syntax. v. I e II, Amsterdam: John Benjamins, 2001.

GREENBERG, J. H. Some universals of grammar with particular reference to the order meaningful elements. In: . (Ed.). Universals of language. Cambridge, MA: MIT Press, 1966.

HAIMAN, John. Natural syntax. Cambridge: Cambridge University Press, 1985.

HOPPER, P. Emergent grammar. Berkeley Linguistics Society, v. 13, p. 139-157, 1987.

KENNAN, E. L.; COMRIE, B. Noun phrase accessibility and universal grammar. Linguistic Inquiry 8,1977.

LAKOFF, G.; JOHNSON, M. Metáforas da vida cotidiana. Trad. GEIM. Campinas, SP: Mercado de Letras, 2002. (Col. As Faces da Linguística Aplicada).

LANGACKER, R. W. Foundations of cognitive grammar. Stanford: Stanford University Press, 1987.

MARTELOTTA, M. E. Mudança linguística: uma abordagem baseada no uso. São Paulo: Cortez, 2011. 
MOLLICA, M. C. de M. O estudo da cópia nas construções relativas em português. Dissertação (Mestrado em Letras), Rio de Janeiro: Pontifícia Universidade Católica do Rio de Janeiro, 1977.

OLIVEIRA, M. R.; VOTRE, S. (Coords.). Corpus Discurso e Gramática - a língua falada e escrita na cidade do Rio de Janeiro. Rio de Janeiro: UFRJ, inédito.

PERINI, M. A. Gramática descritiva do português. 3. ed. São Paulo: Ática, 1998.

SILVA, B. G. S. G. As estratégias de relativização na escrita de portugueses dos séculos XVI, XVII e XVIII. Tese (Doutorado em Letras Vernáculas), Rio de Janeiro: Universidade Federal do Rio de Janeiro, 2011.

TARALLO, F. Relativization Strategies in Brazilian Portuguese. Ph. D. dissertation, Philadelphia: University of Pennsylvania,1983.

TAYLOR, J. R. Linguistic categorization. 2. ed. Oxford: Oxford University Press, 1995.

TOMASELLO, M. (ed.). The new psychology of language. New Jersey: Lawrence Erlbaum, 1998.

TRAUGOTT, E. C. Exaptation and grammaticalization. In: AKIMOTO, M. (ed). Linguistics studies based on corpora. Tokyo: Hituzi Syobo Publishing Company, 2004.

VAREJÃO, F. de O. A. Variação das estratégias de concordância verbal e em estratégias de relativização no português europeu popular. Tese (Doutorado em Língua Portuguesa), Rio de Janeiro: Universidade Federal do Rio de Janeiro, 2006. 